\title{
A New Method for Describing the Atomic-scale Structure of Rusts Formed on the Iron Based Alloy Surfaces
}

\author{
Shigeru SUZUKI, Masatoshi SAITO, ${ }^{1)}$ Masao KIMURA, ${ }^{2)}$ Tamaki SUZUKI, ${ }^{2)}$ Hiroshi KIHIRA ${ }^{2)}$ and \\ Yoshio WASEDA
}

Institute of Multidisciplinary Research for Advanced Materials, Tohoku University, Sendai 980-8577 Japan.

1) School of Health Sciences, Faculty of Medicine, Niigata University, Niigata 951-8518, Japan.

2) Technical Development Bureau, Nippon Steel Corporation, Futtsu 293-8511 Japan.

E-mail: ssuzuki@tagen.tohoku.ac.jp

(Received on September 13, 2002; accepted in final form on October 25, 2002)

\begin{abstract}
Quantitative structural analysis by conventional X-ray diffraction and anomalous X-ray scattering coupled with the reverse Monte-Carlo simulation technique has been carried out, in order to characterize the atomicscale structure of rust formed on the surface of $\mathrm{Fe}, \mathrm{Fe}-2 \% \mathrm{Cr}, \mathrm{Fe}-3 \% \mathrm{Ni}$ and $\mathrm{Fe}-1.6 \% \mathrm{Cu}$ alloys and a weathering steel. Rust samples were prepared by filtering corrosion products formed on the surface of these alloys in salt water. X-ray diffraction patterns showed that main components of the rust consist of ferric oxyhydroxides such as $\gamma$-FeOOH. Radial distribution functions obtained from both conventional X-ray diffraction and anomalous $X$-ray scattering clearly indicated that the fundamental local unit structure in the rust is the octahedral $\mathrm{FeO}_{6}$, although it is likely to be distorted. Realistic atomic arrangements in the rust were estimated by fitting of the ordinary and environmental interference functions calculated using the reverse Monte-Carlo simulation technique. These results provided that the network structure consists of the $\mathrm{FeO}_{6}$ octahedral units and its distortion depend upon the composition of samples. These facts suggest that alloying elements in the rust, which themselves are corroded, play an important role in forming the atomic-scale structure of the rust.
\end{abstract}

KEY WORDS: X-ray diffraction; reverse Monte-Carlo simulation; iron based alloys; weathering steel; rust; corrosion; atomic structure.

\section{Introduction}

The structure of corrosion products or rust formed on the steel surface is of great interest, because corrosion behavior of steel is strongly dependent on the rust. For instance, if rust covers the surface of steel as a protective film, the film is considered to reduce the corrosion rate of steel. Typically, the corrosion rate of weathering steel in atmosphere is known to be considerably suppressed by a rust layer formed on the steel surface. Several conventional analytical methods, such as electron probe microanalysis, infrared spectroscopy, Raman spectroscopy and transmission electron microscopy, have been applied, ${ }^{1-4)}$ in order to characterize the morphology and structure of rust formed on the steel surface. These results provided some interesting information on the composition and structure of rust. Nevertheless, the atomic-scale structure of rust has not been revealed yet. Since rust is formed by reaction of metallic elements, mainly iron, with oxygen and water originated from atmosphere, the structure of rust appears to be very complicated. Thus, the crystallographic structure with the long-range order is not sufficiently confirmed. For this reason, some parts of rust of steel have often been assigned to the amorphous state in previous some works indeed.

Further structural or morphological information has been provided by the recent Mössbauer spectra measurements in the low temperature range between about $10 \mathrm{~K}$ and room temperature, showing that rust formed on the steel surface is attributed to anti-ferromagnetic ferric oxyhydroxides. The rust reveals super-paramagnetism at about room temperature, which suggesting that particles of rust are very fine. ${ }^{5,6)}$ On the other hand, the results by the extended X-ray absorption fine structure (EXAFS) method indicated the fundamental local structure unit of rust is mainly octahedral $\mathrm{FeO}_{6}$ consisting of one iron atom surrounded with six oxygen atoms, and hydrogen atoms are quite likely to be intercalated in these structural units of ferric oxyhydroxides. ${ }^{7,8)}$ However, these interesting results on the morphology and fundamental local structure of rust cannot provide any information about the network of structural units and its deviation from the ideal case. This prompts us to report our own results obtained by X-ray diffraction and anomalous X-ray scattering (AXS), coupled with reverse Monte-Carlo (RMC) simulation. It may be worth mentioning that this quantitative structural analysis has successfully been applied to characterize the atomic-scale structure of various materials in the variety of states such as liquids, glasses, aperiodic systems etc. $^{9-11)}$

The main purpose of this work is to provide the atomicscale structure of rust formed on the surface of iron based 
alloys, containing chromium, nickel or copper, and weathering steel in salt water, because a few percents of these alloying elements are known to be added to iron based alloys in order to improve corrosion protection of steel. It has also been the focusing point of this work to reveal the network structure consisting of $\mathrm{FeO}_{6}$ octahedral units and its distortion from the ideal case found in a typical ferric oxyhydroxide of $\gamma$-FeOOH. This includes how the alloying elements affect on the structure of rust formed on the surface of various iron based alloys and steel.

\section{Experimental}

\subsection{Samples}

Samples of iron, iron- 2.0 mass $\%$ chromium, iron-3.0 mass $\%$ nickel and iron- 1.6 mass $\%$ copper alloys were prepared from pure iron, chromium and nickel by vacuum induction melting. ${ }^{12)}$ These samples were hereafter referred to as $\mathrm{Fe}, \mathrm{Fe}-2 \% \mathrm{Cr}, \mathrm{Fe}-3 \% \mathrm{Ni}$ and $\mathrm{Fe}-1.6 \% \mathrm{Cu}$, respectively. A commercial weathering steel referred to as WS, of which the chemical composition is $0.10 \% \mathrm{C}, 0.050 \% \mathrm{Si}, 0.50 \%$ $\mathrm{Mn}, 0.096 \% \mathrm{P}, 0.016 \% \mathrm{~S}, 0.15 \% \mathrm{Ni}$ and $0.56 \% \mathrm{Cr}$ in mass $\%$, was also utilized. The iron based alloys and steel were shaped to $10 \mathrm{~mm}$ square sheets of $1 \mathrm{~mm}$ in thickness. They were leached in artificial seawater with 2.5 mass $\%$ $\mathrm{NaCl}, 1.1$ mass $\% \mathrm{MgCl}_{2}, 0.4$ mass $\% \mathrm{Na}_{2} \mathrm{SO}_{4}$ and 0.07 mass $\%$ $\mathrm{KCl}$ at room temperature for about 15 days, so as to form colloidal corrosion products, from which powder rust samples were obtained by filtering. The structures of the corrosion products were almost independent of leaching time.

\subsection{Measurements And analysis}

Conventional X-ray diffraction experiments were carried out using $\mathrm{Cu} K \alpha$ radiation, in order to identify constituents of rust. Also, precise X-ray diffraction measurements were performed with Mo $K \alpha$ radiation, which was generated at a power of $18 \mathrm{~kW}$ by Rigaku RINT-2000. The diffracted Xray from samples was separated by a graphite monochromator. In both cases, the scattering X-ray intensities were measured in a wide range of wave vector, in order to obtain the atomic-scale structure with sufficiently reliable resolution.

Anomalous X-ray scattering (AXS) measurements were made for estimating the environmental interference function for Fe in rust. The beam line used for the AXS measurements was in BL-7C of Photon Factory, High Energy Accelerator Research Organization. AXS measurements were carried out with radiations of incident energies of 7.0682 and $6.8112 \mathrm{keV}$. These energies correspond to 25 and $300 \mathrm{eV}$ below the $\mathrm{Fe} \mathrm{K}$ absorption edge, respectively. Details of these AXS measurements are described elsewhere. $^{11)}$

The fundamental local structure of $\mathrm{FeO}_{6}$ in rust is determined using the least mean square refining method for the interference functions. ${ }^{13,14)}$ The network structure consisting of $\mathrm{FeO}_{6}$ octahedral units in rust, corresponding to the middle-range ordering structure, was obtained using the reverse Monte-Carlo simulation hereafter referred to as RMC technique. ${ }^{15)}$ In this simulation, we started with an initial configuration of 4320 particles positioned in a super cell and the computed interference functions were compared

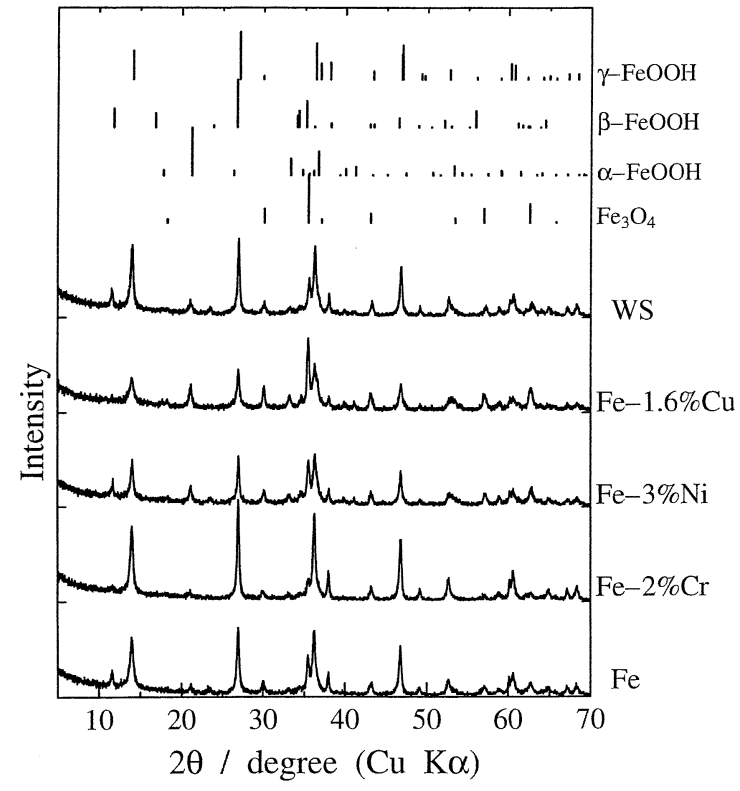

Fig. 1. X-ray diffraction patterns of rust formed on $\mathrm{Fe}, \mathrm{Fe}-$ $2 \% \mathrm{Cr}, \mathrm{Fe}-3 \% \mathrm{Ni}, \mathrm{Fe}-1.6 \% \mathrm{Cu}$ and WS.

with two independent experimental data of the ordinary and environmental interference functions. A new configuration is then generated by the random movement of particles and computed the interference functions. Such iterative process is made until we get a reasonable convergence. The RMC procedure is identical to that used in our previous works. ${ }^{9,10)}$ Finally, the partial pair distribution between two atoms, $\mathrm{Fe}-\mathrm{O}, \mathrm{Fe}-\mathrm{Fe}$ and $\mathrm{O}-\mathrm{O}$ pairs were estimated in this work.

\section{Results and Discussion}

\subsection{X-ray Scattering Intensity and RDFs}

Figure 1 shows the intensity patterns of six rust samples, together with the diffraction lines of $\mathrm{Fe}_{3} \mathrm{O}_{4}, \alpha$-FeOOH, $\beta$ $\mathrm{FeOOH}$ and $\gamma-\mathrm{FeOOH}$ given by JCPDS. These results indicate that a main component of the rust is attributed to $\gamma$ $\mathrm{FeOOH}$ and small amounts of $\alpha$-FeOOH, $\beta$-FeOOH and $\mathrm{Fe}_{3} \mathrm{O}_{4}$ are also contained in the rust depending on the sample species. In order to get insight into the atomic-scale structure of rust consisting mainly of $\gamma$-FeOOH formed on the surface of $\mathrm{Fe}, \mathrm{Fe}-2 \% \mathrm{Cr}, \mathrm{Fe}-3 \% \mathrm{Ni}, \mathrm{Fe}-1.6 \% \mathrm{Cu}$ and $\mathrm{WS}$, the interference functions over a wide range of wave vector were obtained from diffraction measurements using Mo $K \alpha$ radiation. These results are shown in Fig. 2. In these profiles, small peaks other than $\gamma-\mathrm{FeOOH}$ are removed for further quantitative structural analysis.

Environmental structural information for iron in rust is obtained by measuring X-ray scattering intensity profiles at incident energies of 7.0682 and $6.8112 \mathrm{keV}$, which correspond to energies 25 and $300 \mathrm{eV}$ below the Fe $\mathrm{K}$ absorption edge, respectively. The results are shown in Fig. 3, using the $\mathrm{Fe}-2 \% \mathrm{Cr}$ case as an example. A differential X-ray intensity profile of rust formed on $\mathrm{Fe}-2 \% \mathrm{Cr}$ at the top of Fig. 3 , which was obtained from two intensity profiles measured at incident energies of 7.0682 and $6.8112 \mathrm{keV}$ in the bottom. These differential profiles obtained in different samples in a similar manner were utilized for analyzing the en- 


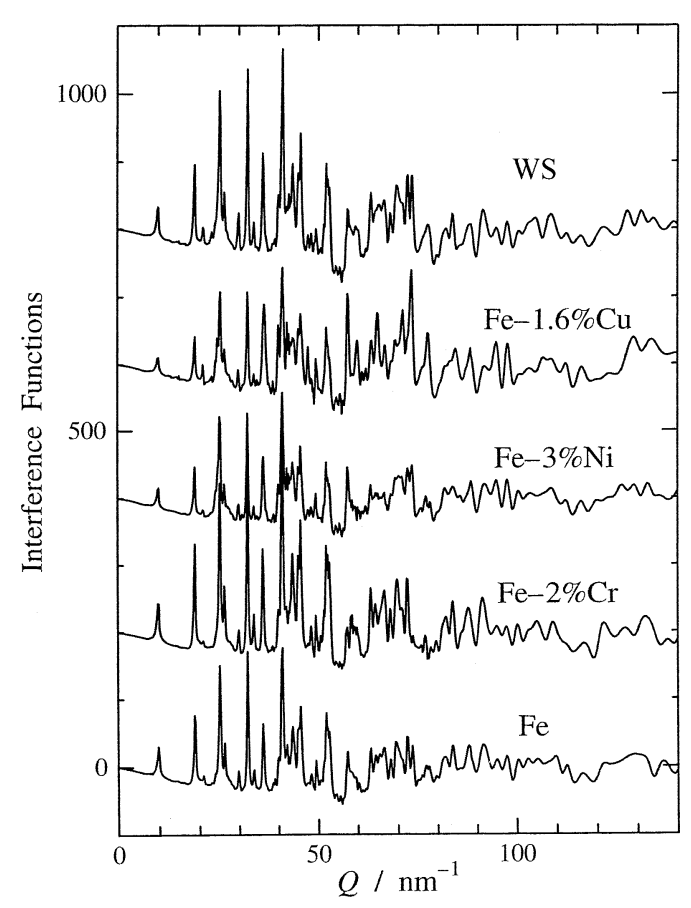

Fig. 2. Interference functions of rust formed on $\mathrm{Fe}, \mathrm{Fe}-2 \% \mathrm{Cr}$, $\mathrm{Fe}-3 \% \mathrm{Ni}, \mathrm{Fe}-1.6 \% \mathrm{Cu}$ and $\mathrm{WS}$

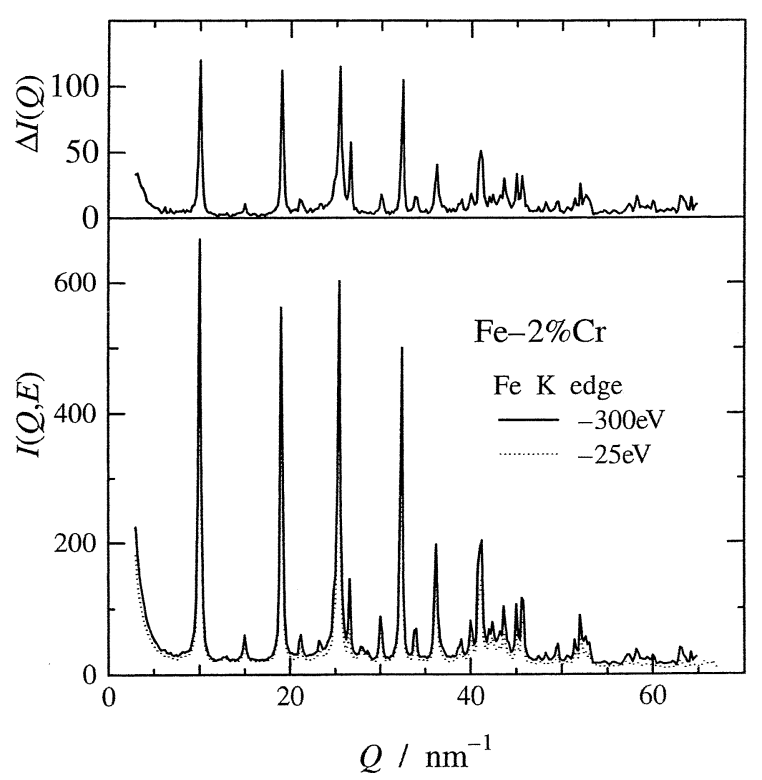

Fig. 3. Differential X-ray intensity profile (top) of rust formed on $\mathrm{Fe}-2 \% \mathrm{Cr}$ obtained from the intensity profiles (bottom) measured at incident energies of 7.0682 and 6.8112 $\mathrm{keV}$, which correspond to the energies 25 and $300 \mathrm{eV}$ below the Fe absorption edge, respectively.

vironmental interference functions for $\mathrm{Fe}$.

Figure 4 shows the ordinary radial distribution functions (RDF) for the $\gamma$-FeOOH component formed on the surface of $\mathrm{Fe}, \mathrm{Fe}-2 \% \mathrm{Cr}, \mathrm{Fe}-3 \% \mathrm{Ni}, \mathrm{Fe}-1.6 \% \mathrm{Cu}$ and $\mathrm{WS}$, which were obtained by Fourier-Transformation of the interference functions given by Fig. 2 . These results clearly suggest there are some differences in the atomic-scale structure of five rust samples. Such features can be readily seen in Fig. 5, which provides the superimposed RDFs in the range 0 $0.5 \mathrm{~nm}$. For example, the peaks detected at about 0.2 and $0.3 \mathrm{~nm}$ in the RDFs are attributed to the pair coordination

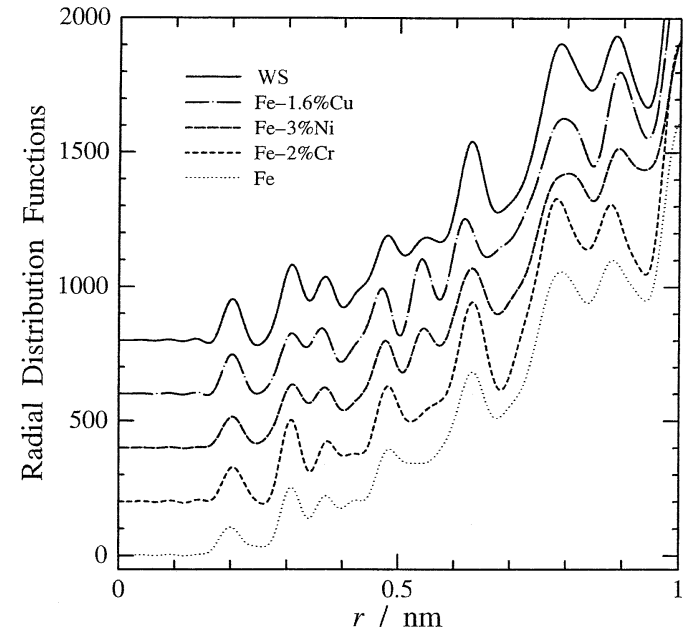

Fig. 4. Radial distribution functions of rust formed on $\mathrm{Fe}, \mathrm{Fe}-$ $2 \% \mathrm{Cr}, \mathrm{Fe}-3 \% \mathrm{Ni}, \mathrm{Fe}-1.6 \% \mathrm{Cu}$ and $\mathrm{WS}$.

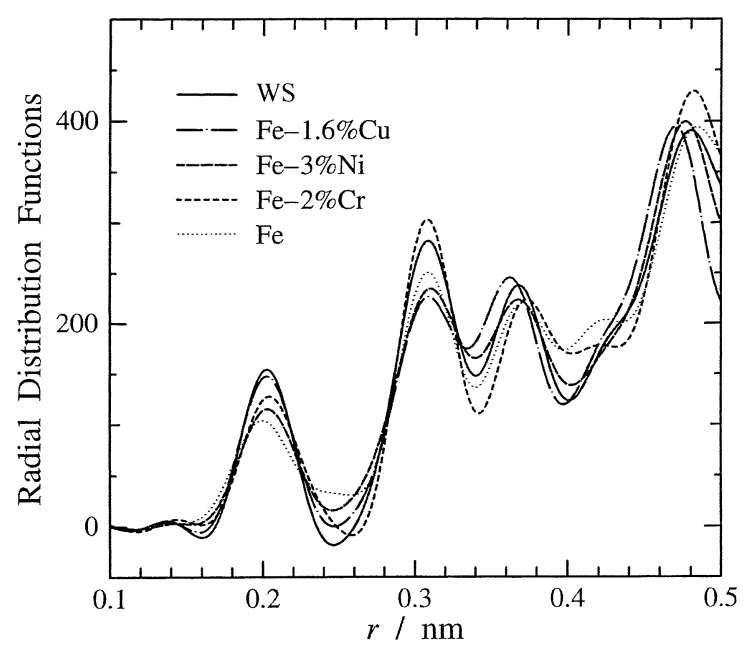

Fig. 5. Enlarged drawing of the radial distribution functions of rust formed on $\mathrm{Fe}, \mathrm{Fe}-2 \% \mathrm{Cr}, \mathrm{Fe}-3 \% \mathrm{Ni}, \mathrm{Fe}-1.6 \% \mathrm{Cu}$ and WS.

of $\mathrm{Fe}-\mathrm{O}$ and $\mathrm{Fe}-\mathrm{Fe}$, respectively. It should be kept in mind here that the different weighting factors are used for all five samples, although the amounts of alloying elements are a few percent. Then, only the direct comparison for the peak position is significant with respect to these RDFs.

\subsection{Distortion of $\mathrm{FeO}_{6}$ Octahedral Unit from That Found in $\gamma$-FeOOH}

The fundamental local unit in the rust characterized by the coordination number and atomic distance, that is the $\mathrm{FeO}_{6}$ octahedra in $\gamma$-FeOOH, can be evaluated using the least-squares refining method for both the ordinary and environmental interference functions. The structural parameters were determined so as to minimize differences between calculation and the experimental data in these two interference functions. The resultant structural parameters are summarized in Fig. 6, together with the average square displacements of atoms. These results confirm that the fundamental local unit structure of all six rust samples is the octahedral $\mathrm{FeO}_{6}$, similar to those found in $\gamma$-FeOOH. The relatively large peak broadening in RDFs, corresponding to the $\mathrm{Fe}-\mathrm{O}$ pair, is found and it implies that the deviation of 


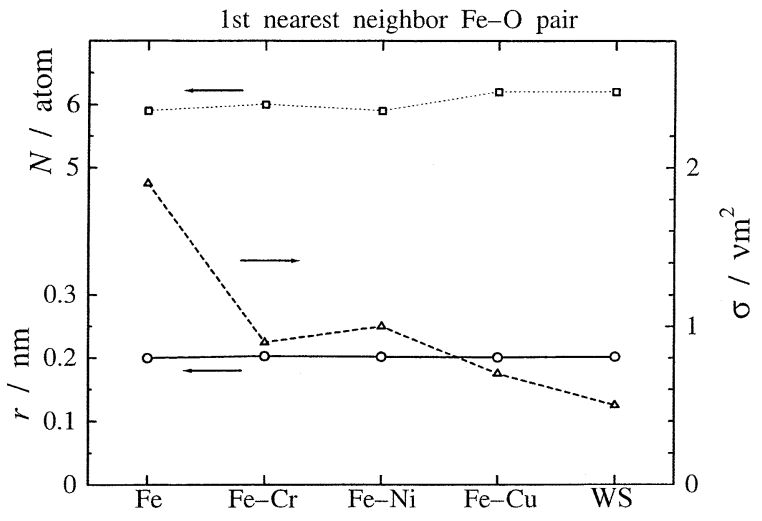

Fig. 6. Atomic distance and coordination number for the nearest neighbor $\mathrm{Fe}-\mathrm{O}$ pair in rust formed on $\mathrm{Fe}, \mathrm{Fe}-2 \% \mathrm{Cr}$, $\mathrm{Fe}-$ $3 \% \mathrm{Ni}, \mathrm{Fe}-1.6 \% \mathrm{Cu}$ and $\mathrm{WS}$.

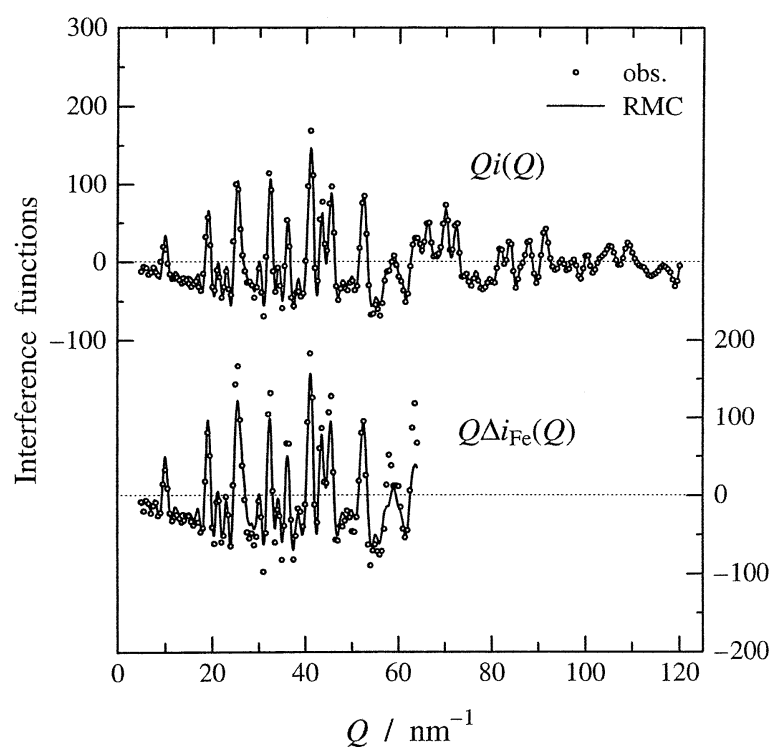

Fig. 7. The ordinary interference functions $Q i(Q)$ and environmental interference functions $Q \Delta i(Q)$ for $\mathrm{Fe}$ of rust formed on $\mathrm{Fe}-2 \% \mathrm{Cr}$. Open circles and solid lines denote the experimental data and calculated values using RMC.

the $\mathrm{FeO}_{6}$ octahedral unit from the ideal case may be described in the order of $\mathrm{Fe}, \mathrm{Fe}-3 \% \mathrm{Ni}, \mathrm{Fe}-2 \% \mathrm{Cr}, \mathrm{Fe}-$ $1.6 \% \mathrm{Cu}$ and $\mathrm{WS}$.

\subsection{Distortion of Network of $\mathrm{FeO}_{6}$ Octahedral Units from That Found in $\boldsymbol{\gamma}$-FeOOH}

The network structure consisting of the $\mathrm{FeO}_{6}$ octahedral units in rust, corresponding to the middle-range ordering structure, was evaluated from the ordinary interference function $Q i(Q)$ and environmental interference functions $Q \Delta i_{\mathrm{Fe}}(Q)$ using the RMC simulation. In this data processing, the atomic arrangements in the $\gamma$-FeOOH components can be estimated by comparing the calculated interference functions with the experimental data. Figure 7 shows a comparison of the ordinary interference function $Q i(Q)$ and environmental interference functions $Q \Delta i_{\mathrm{Fe}}(Q)$ for $\mathrm{Fe}$ using the case of $\mathrm{Fe}-2 \% \mathrm{Cr}$. Open circles denote the experimental data and solid lines are the results calculated by the RMC simulation. Such RMC simulation process was applied to other four cases; $\mathrm{Fe}, \mathrm{Fe}-3 \% \mathrm{Ni}, \mathrm{Fe}-1.6 \% \mathrm{Cu}$ and $\mathrm{WS}$. The resultant partial pair distribution functions of (a) $\mathrm{Fe}-\mathrm{O}$, (b)
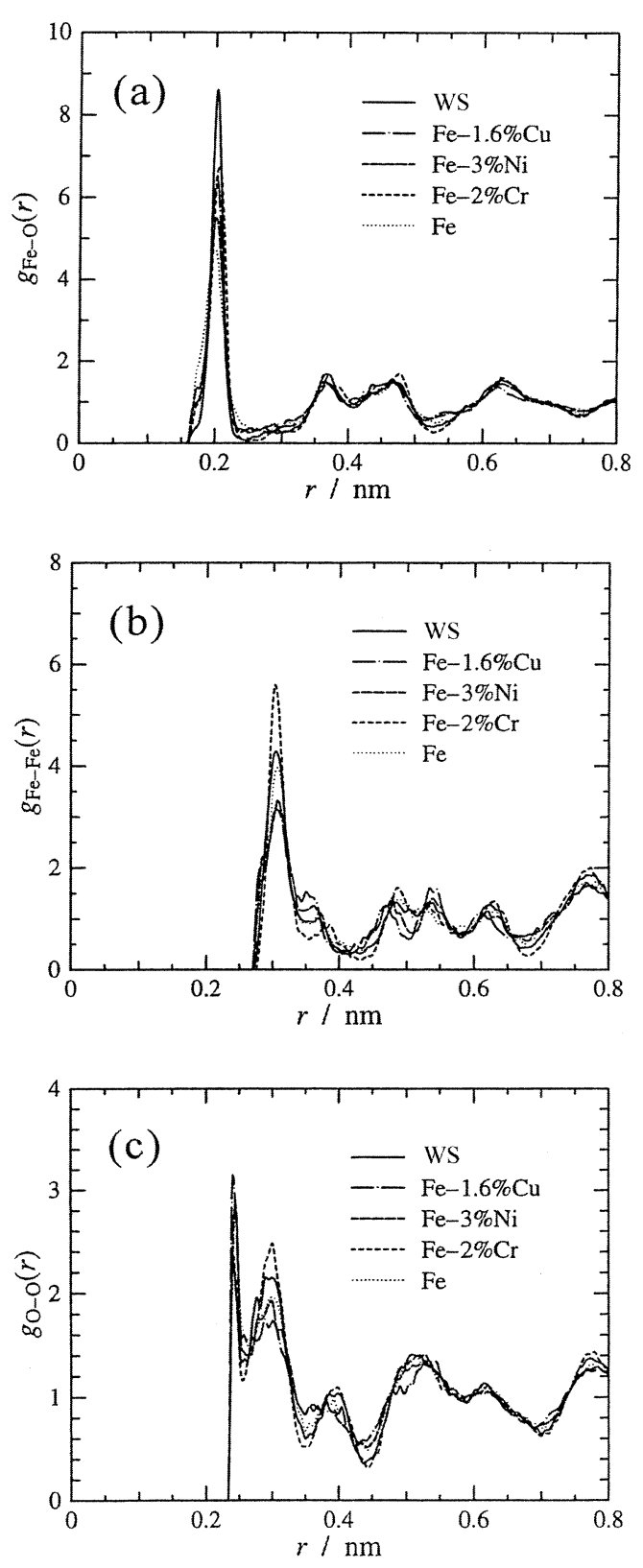

Fig. 8. Partial pair distribution functions of (a) $\mathrm{Fe}-\mathrm{O}$, (b) $\mathrm{Fe}-\mathrm{Fe}$ and (c) $\mathrm{O}-\mathrm{O}$ pairs of rust formed on $\mathrm{Fe}, \mathrm{Fe}-2 \% \mathrm{Cr}, \mathrm{Fe}-$ $3 \% \mathrm{Ni}, \mathrm{Fe}-1.6 \% \mathrm{Cu}$ and $\mathrm{WS}$ estimated by RMC simulation.

$\mathrm{Fe}-\mathrm{Fe}$ and (c) $\mathrm{O}-\mathrm{O}$ pairs of rust on $\mathrm{Fe}, \mathrm{Fe}-2 \% \mathrm{Cr}$, $\mathrm{Fe}-3 \% \mathrm{Ni}, \mathrm{Fe}-1.6 \% \mathrm{Cu}$ and $\mathrm{WS}$ shown in Fig. 8. The pair distribution functions of $g_{\mathrm{Fe}-\mathrm{O}}(r)$ are found to vary from one sample to another sample. For example, the first peak of the $g_{\mathrm{Fe}-\mathrm{O}}(r)$ for rust formed on WS is very sharp and the highest, while the completely opposite feature is observed in $g_{\mathrm{Fe}-\mathrm{O}}(r)$ for rust formed on Fe. These results are consistent with those found in Fig. 5. On the other hand, the height of the first peak in $g_{\mathrm{Fe}-\mathrm{Fe}}(r)$ is given in the order of $\mathrm{Fe}-2 \% \mathrm{Cr}$, $\mathrm{WS}, \mathrm{Fe}, \mathrm{Fe}-1.6 \% \mathrm{Cu}$ and $\mathrm{Fe}-3 \% \mathrm{Ni}$. The deviation of the network structure consisting of $\mathrm{FeO}_{6}$ octahedral units from the ideal $\gamma$-FeOOH case is quite likely to be found. Such deviation may be characterized by the $g_{\mathrm{Fe}-\mathrm{Fe}}(r)$ correlation. For this reason, the atomic arrangements in the $\gamma-\mathrm{FeOOH}$ component in rust have been estimated by visualizing the atomic distortion from the partial distribution functions.

The network structure consisting of the $\mathrm{FeO}_{6}$ octahedral 

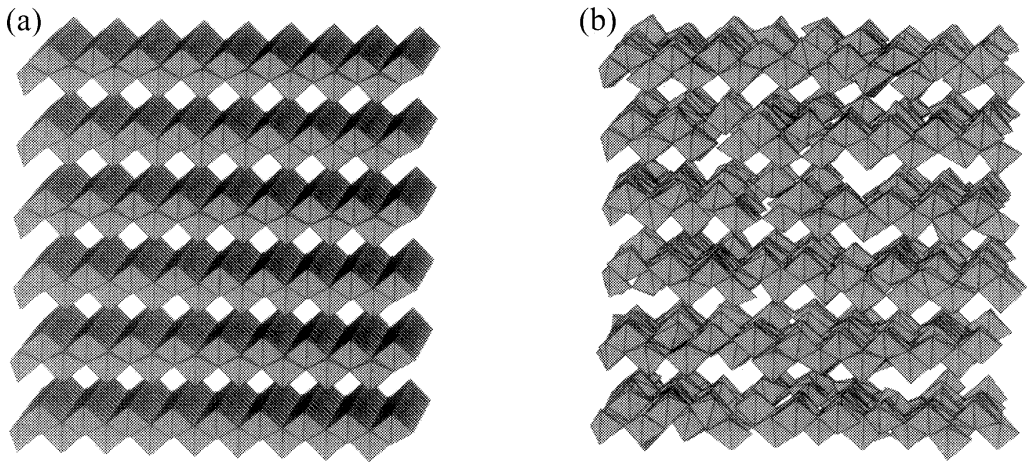

Fig. 9. Arrangement of the $\mathrm{FeO}_{6}$ octahedral units in (a) ideal $\gamma$-FeOOH structure and (b) rust formed on $\mathrm{Fe}-2 \% \mathrm{Cr}$.
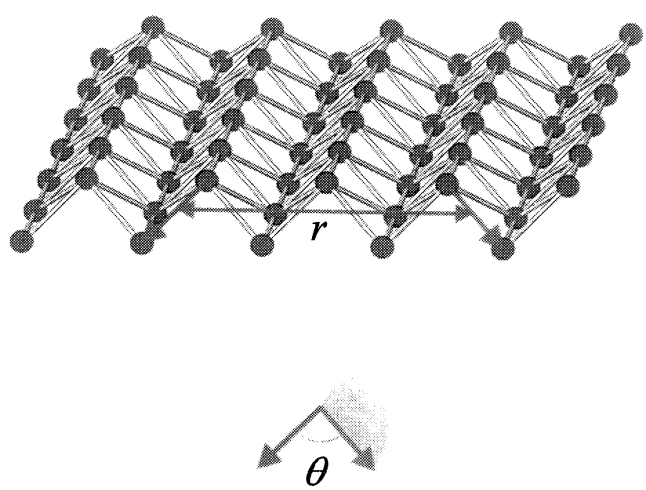

Fig. 10. Schematic diagram for analyzing the network structure of rust by estimating bond angle distribution $B(\theta, r)$ between $\mathrm{Fe}-\mathrm{Fe}$ pairs.

units is given in Fig. 9, using the ideal $\gamma$-FeOOH structure and the $\gamma$-FeOOH component in rust formed on the surface of $\mathrm{Fe}-2 \% \mathrm{Cr}$. Information corresponding to the middlerange ordering structure can be estimated by the RMC simulation. As easily seen from the results of Fig. 9, the deviation of network structure from the ideal $\gamma$-FeOOH is clearly observed and it has been quantified in rust formed on the surface of $\mathrm{Fe}-2 \% \mathrm{Cr}$, when applying the $\mathrm{RMC}$ technique to both the ordinary and environmental interference functions.

\subsection{Contour Map Displaying Network Distortion}

A new method for visually displaying the deviation of the network structure from the ideal $\gamma$-FeOOH case will be proposed by interpreting two parameters. Figure 10 shows a schematic diagram of the network, in which a bond angle between different orientations of two iron atoms in the network of the $\mathrm{FeO}_{6}$ octahedral units, $\theta$, and a distance between the two $\mathrm{Fe}-\mathrm{Fe}$ pairs, $r$, are defined. In the ideal $\gamma$ FeOOH case, bond angle $\theta$ can be mainly found at about 0 , 60,90 and 120 degrees. The present authors maintain the view that the bond angle distribution $B(\theta, r)$ between $\mathrm{Fe}-\mathrm{Fe}$ pairs as a function of angle $\theta$ and distance $r$ represents the deviation of the network structure from the ideal case. Although the bond angle distribution itself is three-dimensionally displayed as a function of angle $\theta$ and distance $r$, contour maps of the bond angle distribution for a sample and the differential data between two samples are convenient for explaining the deviation of the network structure consisting of the $\mathrm{FeO}_{6}$ octahedral units for samples of interest.

Figure 11 exemplify contour maps of differential bond angle distributions $\Delta B(\theta, r)$, which are obtained from bond angle distributions $B(\theta, r)$ for rust formed on $\mathrm{Fe}-2 \% \mathrm{Cr}$ and $\mathrm{Fe}-3 \% \mathrm{Ni}$ with a reference of rust formed on $\mathrm{Fe}$. The bond angle distribution $B(\theta, r)$ for rust formed on the surface of $\mathrm{Fe}$ is included in this figure for reference. Relative variations in $\Delta B(\theta, r)$ and $B(\theta, r)$ are displayed in pseudo-color in Fig. 11, in which the color scale is also given. The bond angle distribution $B(\theta, r)$ for rust formed on $\mathrm{Fe}$, as shown in Fig. 11(c), reveals high frequencies at specific angles $\theta$ of about $0,60,90$ and 120 degrees, but it somewhat broadens around these angles, implying that the network structure is distorted. In the differential bond angle distributions $\Delta B(\theta, r)$ for iron based alloys and steel, as shown in Figs. 11(a) and 11(b), positive values (red and yellow) are found at angles of about 0, 60, 90 and 120 degrees for rust formed on $\mathrm{Fe}-2 \% \mathrm{Cr}$. This quantitatively indicates that the distortion of the network structure in rust formed on $\mathrm{Fe}-2 \% \mathrm{Cr}$ is smaller than that for $\mathrm{Fe}$. On the other hand, negative values in the differential bond angle distribution (blue) are observed at angles of about 0, 60, 90 and 120 degrees for rust formed on $\mathrm{Fe}-3 \% \mathrm{Ni}$, which indicates that the large distortion of the network structure of this sample is rather quantified in comparison with the Fe case.

\subsection{Effect of Alloying Elements on Distortion of the $\mathrm{FeO}_{6}$ Octahedral Units and Their Network Structure}

The atomic-scale structure of the $\gamma-\mathrm{FeOOH}$ component in rust formed on iron based alloys and weathering steel has been characterized using the distortion of the $\mathrm{FeO}_{6}$ octahedral units and their network structure in this work. It would be very interesting to note that the atomic-scale structure of the $\gamma$-FeOOH component in the rust samples presently investigated significantly depend on these iron based alloys. This implies that structural units containing a certain alloying element formed during corrosion are, more or less, occupy sites of the $\mathrm{FeO}_{6}$ octahedral units. Such occupation may influence not only the short-range ordering but also middle-range ordering characterized by the $\mathrm{FeO}_{6}$ octahedral units as observed in this work. Thus, the alloying elements are considered to play an important role in the formation processes of the atomic scale structure of rust, although hydrogen in the rust structure, which is not made clear yet, may also be important. Since these effects of alloying elements may directly or indirectly influence physical and chemical properties of rust, the present atomic-scale structural information appears to give one of the factors for con- 
(a) $\mathrm{Fe}-2 \% \mathrm{Cr}-\mathrm{Fe}$

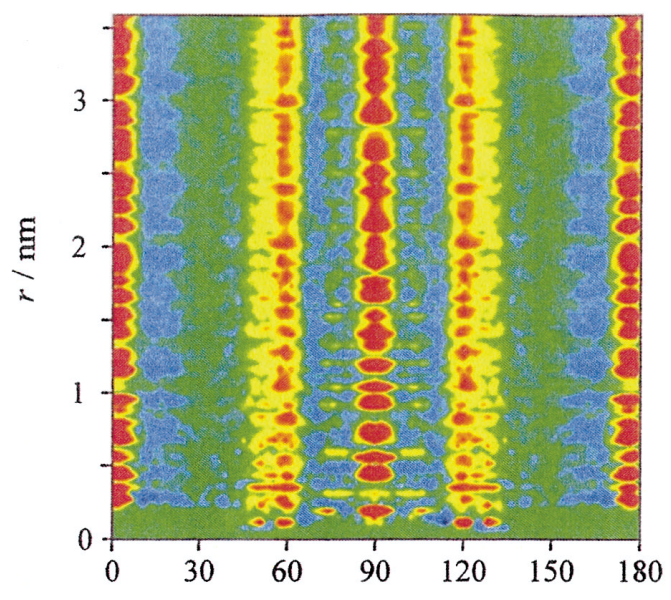

Angle / deg.

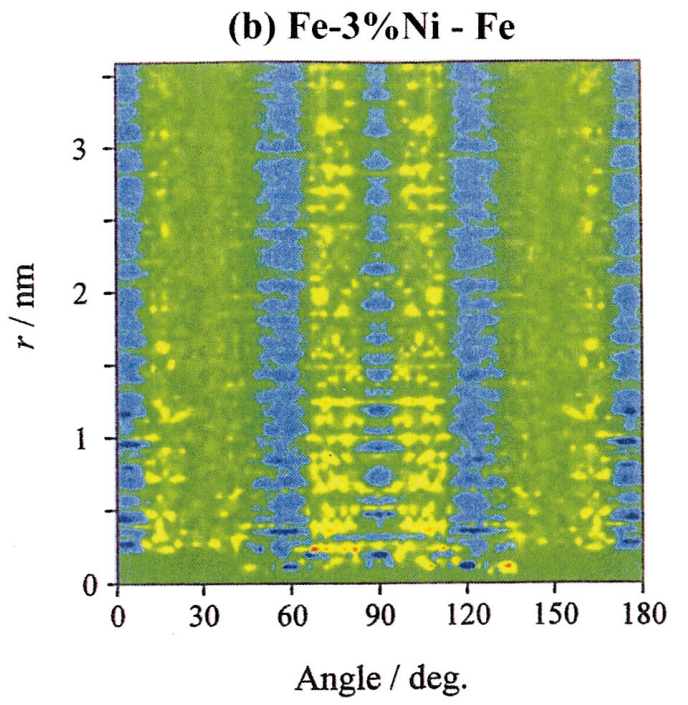

(c) $\mathrm{Fe}$

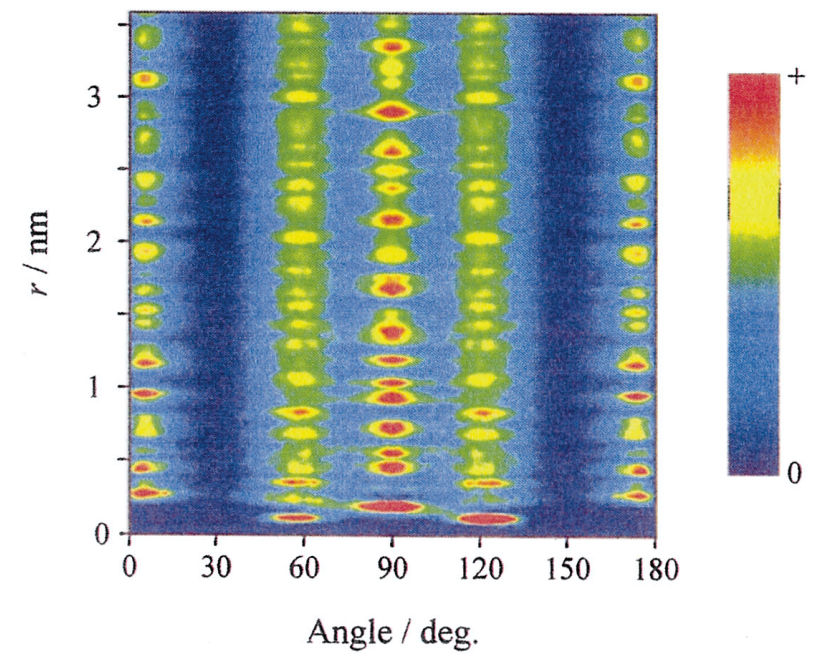

Fig. 11. Contour map of differential bond angle distributions $\Delta B(\theta, r)$ of rust formed on (a) $\mathrm{Fe}-2 \% \mathrm{Cr}$ and (b) $\mathrm{Fe}-$ $3 \% \mathrm{Ni}$ with respects to rust formed on $\mathrm{Fe}$, and bond angle distribution $B(\theta, r)$ of rust formed on $\mathrm{Fe}$. trolling or designing the protective rust formed on steel.

The present work has demonstrated clear differences in the atomic-scale structure of rust formed on different iron based alloys and steel. Within the best knowledge of the present authors, systematic differences in the atomic-scale structure of rust formed on iron and steel were quantified in this work for the first time. In addition, the method used in this work is considered to be one way to reduce the difficulty in subject on structural characterization of rust, which is still in controversy. Although only quantitative analyses of the atomic-scale structure in the $\gamma$ - $\mathrm{FeOOH}$ component of rust formed in salt water has been focused in this work, structural analyses the other rust components, such as $\alpha$ $\mathrm{FeOOH}$ and $\mathrm{Fe}_{3} \mathrm{O}_{4}$, are also required. Such work is under consideration. Alloying elements in these rust components are likely to act on the structure and properties of rust in some manners, and the present methods may be promising for characterizing structural changes of rust by alloying elements. By a series of these structural analyses together with corrosion experiments, conditions for forming protective rust layers on low-alloyed steel may be optimized.

\section{Concluding remarks}

Quantitative structural analyses by X-ray diffraction and anomalous X-ray scattering coupled with the reverse Monte-Carlo simulation technique have been used for characterizing the atomic-scale structure of rust, $\gamma-\mathrm{FeOOH}$, formed on the surface of $\mathrm{Fe}, \mathrm{Fe}-2 \% \mathrm{Cr}, \mathrm{Fe}-3 \% \mathrm{Ni}$ and $\mathrm{Fe}-$ $1.6 \% \mathrm{Cu}$ alloys and a weathering steel. The main concluding remarks are as follows:

(1) Radial distribution functions obtained from the Xray diffractions and anomalous X-ray scattering data indicated that the fundamental local unit structure in rust is the octahedral $\mathrm{FeO}_{6}$. This $\mathrm{FeO}_{6}$ structure is slightly distorted, depending on the sample and such distortion is given in the order of $\mathrm{Fe}, \mathrm{Fe}-3 \% \mathrm{Ni}, \mathrm{Fe}-2 \% \mathrm{Cr}, \mathrm{Fe}-1.6 \% \mathrm{Cu}$ and $\mathrm{WS}$.

(2) Partial pair distribution functions for rust of five samples were estimated from both the ordinary and environmental interference functions experimentally obtained using the reverse Monte-Carlo simulation technique. The results also suggest the deviation of the network structure consisting of the $\mathrm{FeO}_{6}$ octahedral units from the ideal case.

(3) A new method was proposed for describing the deviation of the network structure consisting of the $\mathrm{FeO}_{6}$ octahedral units. The present results enable us to quantitatively provide information about the distortion of the network structure and it may be described in the order of $\mathrm{Fe}-3 \% \mathrm{Ni}$, $\mathrm{Fe}-1.6 \% \mathrm{Cu}, \mathrm{Fe}$, WS and $\mathrm{Fe}-2 \% \mathrm{Cr}$. These results suggest that a few percents of alloying elements in iron and steel play an important role in forming the atomic-scale structure of the rust.

\section{Acknowledgements}

The authors wish express their gratitude to Prof. M. Nomura, Photon Factory, High Energy Accelerator Research Organization, for his help on AXS measurements (Proposal No. 2001G273). They should also like to thank Prof. T. Murata, Prof. E. Matsubara and Dr. M. Hashimoto for his discussion with the authors. 
ISIJ International, Vol. 43 (2003), No. 3

\section{REFERENCES}

1) H. Okada, Y. Hosoi, K. Yukawa and H. Narita: Tetsu-to-Hagané, 55 (1969), 355.

2) T. Misawa, K.Asami, K. Hashimoto and S. Shimodaira: Corros. Sci., 14 (1974), 279

3) H. Kihira, S. Ito and T. Murata: Corrosion, 45 (1989), 347.

4) M. Yamashita, H. Miyuki, Y. Matsuda, H. Nagano and T. Misawa: Corros. Sci. 36 (1994), 283

5) T. Okada, Y. Ishii, T. Mizoguchi, I. Tamura, Y. Kobayashi, Y. Takagi, S. Suzuki, H. Kihira, M. Itoh, A. Usami, K. Tanabe and K. Masuda: Jpn. J. Appl. Phys., 39 (2000), 3382.

6) T. Kamimura and S. Nasu: Mater.Trans. JIM, 41 (2000), 1208.
7) S. Suzuki, T. Suzuki, M. Kimura, Y. Takagi, K. Shinoda, K. Tohji and Y. Waseda: J. Appl. Surf. Sci., 169-200 (2001), 109.

8) M. Kimura, T. Suzuki, G. Shigesato, M. Saito, S. Suzuki, H. Kihira, K. Tanabe and Y. Waseda: J. Jpn. Inst. Met., 66 (2002), 166.

9) M. Saito, S. Kang and Y. Waseda: Jpn J. Appl. Phys., 38 (1999), 596.

10) M. Saito, S. Kang and Y. Waseda: J. Phys. Sic. Jpn., 68 (1999), 1932.

11) Y. Waseda: Anomalous X-Ray Scattering for Materials Characterization, Springer-Verlag, Heidelberg, (2002), 111.

12) S. Suzuki: Z. Metallkd., 82 (1993), 883.

13) A. H. Narton and H. A. Levy: Science, 160 (1972), 447.

14) A. H.Narton: H. Chem. Phys., 56 (1972), 1905.

15) R. L. McGreevy and L. Pusztai: Mol. Simul., 1 (1988), 359. 